\title{
Review
}

\section{Non-Clear Cell Renal Cell Carcinoma: Current Management and Best Practice}

\author{
Meghan Salgia, Jacob Adashek, Paulo Bergerot and Sumanta K. Pal* \\ Department of Medical Oncology and Experimental Therapeutics, City of Hope Comprehensive Cancer Center, \\ Duarte, CA, USA
}

\begin{abstract}
The treatment of metastatic renal cell carcinoma (mRCC) has evolved markedly over the past several decades; first with the introduction of targeted therapies and more recently with data supporting checkpoint inhibition. However, the vast majority of studies to date have explored the benefit of agents specifically in the context of clear cell disease. For the estimated $15-20 \%$ of patients with non-clear cell histology, there is little consensus around best practice. Herein, we discuss emerging datasets providing biologic characterization of non-clear cell RCC and identify trials that exploit this biology.
\end{abstract}

Keywords: Papillary, chromophobe, collecting duct

\section{INTRODUCTION}

Biologic classification of clear cell renal cell carcinoma (RCC) has transformed clinical outcomes for patients with metastatic RCC (mRCC). First, recognition of $\mathrm{mRCC}$ as a disease propagated by immune evasion fueled the development of high-dose interleukin-2 (HD IL-2). The US FDA approval of HD IL-2 marked a key milestone, but admittedly, only a small proportion of patients obtained a durable response with this strategy $[1,2]$. The next landmark development exploited alterations in the Von Hippel Lindau (VHL) gene, estimated to be altered in more than half of patients with this disease [3]. VHL protein was noted to play a role in degradation of hypoxia inducible factor (HIF) and accumulation of HIF in the context of $V H L$ alteration led to increased production of vascular endothelial growth factor (VEGFR) [4].

\footnotetext{
*Correspondence to: Sumanta K. Pal, MD, Department of Medical Oncology and Experimental Therapeutics, City of Hope Comprehensive Cancer Center, 1500 East Duarte Road, Duarte, CA 91010, USA. Tel.: +1 626256 4673; Fax: +1 626301 8233; E-mail: spal@coh.org.
}

Multiple agents have been devised to block VEGF and its downstream mediator, the mammalian target of rapamycin (mTOR), inhibiting angiogenesis and other pro-tumor processes [5-14].

After treatment with VEGF-directed therapies, resistance mechanisms have been identified including immune escape with fluxes in cytokines and immune cell subsets (e.g., myeloid derived suppressor cells [MDSCs]) [15]. Checkpoint inhibitors (programmed death-1 (PD-1) and cytotoxic T-lymphocyte associated protein 4 (CTLA4)) have significant efficacy in clear cell disease and other receptor tyrosine kinases (RTKs), such as MET, AXL, and fibroblast growth factor receptor (FGFR) may also serve as bypass mechanisms [16-19]. Agents such as cabozantinib exhibit dual blockade of VEGFR, MET, and AXL, and the recently approved lenvatinib administered with everolimus blocks VEGFR and FGFR [20, 21].

The paradigm for clinical development in nonclear cell RCC has been relatively straightforward to date. Agents developed for non-clear cell mRCC have been applied in groups of patients with mRCC, but the results thus far have been rather dismal. Although 
the phase III assessment of temsirolimus did permit patients with non-clear cell histology, this represented only a small subset of the overall study population [22]. The approach taken thus far fails to acknowledge that mRCC is a heterogeneous disease with each subtype bearing a distinct biology. Herein, we focus on several subtypes for which sufficiently large genomic datasets are available. We then discuss therapeutic approaches that are in place to cater to some of the more common non-clear cell histologies, such as papillary disease.

\section{GENOMIC DATA FOR NON-CLEAR CELL RCC}

\section{Papillary RCC}

The Cancer Genome Atlas (TCGA) investigators have reported an assessment of 161 papillary RCC specimens using several methods including whole exome sequencing, DNA methylation analysis, messenger RNA (mRNA) sequencing, and proteomic analysis [23]. Notably, most patients in this cohort $(71 \%)$ were characterized as having non-metastatic disease and only $3 \%$ of patients were noted to have metastases; with the remainder of patients having unknown staging [23]. The most notable alterations cited in this cohort included mutations in the MET proto-oncogene in type I patients and NRF2-ARE mutations in patients with type II disease [23]. $C D K N 2 A$ loss was also more frequent in the latter group [23].

Our group has recently reported data pertaining to a similarly sized cohort of 169 patients with papillary RCC who had genomic profiling completed though a CLIAA-certified laboratory (Foundation Medicine, Inc.; Cambridge, MA) [24]. The series reflects to a greater extent patients with advanced disease; $61 \%$ of patients are stage IV, while $21 \%$ of patients are stage III [24]. A minority of patients $(13 \%)$ were defined as having stage I or II disease [24]. This distinction yielded key differences in the ascertained genomic profile. Patients in our study (both type 1 and 2) had a higher frequency of MET mutation and copy number alteration [24]. Certain potentially actionable mutations, such as $N F 2$ or SMARCB1, were considerably more frequent in type 2 disease in our study [24]. Elements in the SWI/SNF pathway (including SMARCB1, SMARCA4, PBRM1, ARIDIA, ARIDIB and $A R I D 2)$ were more common in type 2 disease as well [24].

\section{Chromophobe RCC}

Chromophobe RCC is less frequent than papillary RCC representing approximately $5 \%$ of all cases [25]. The TCGA investigators have also reported an assessment of 66 patients with chromophobe RCC [26]. The most frequently noted alterations were in the TERT promoter region [26]. Assessment of mitochondrial DNA in this effort led to the suggestion that changes in mitochondrial function may play a role in disease biology [26]. Casuscelli and colleagues have recently reported an even larger dataset including 79 patients with chromophobe RCC, uniquely including 38 patients with metastatic disease [27]. In the overarching dataset, the most frequently noted alterations were in TP53 (39\%), PTEN (15\%), ATM (9\%), and ARIDIB (9\%) [27]. Amongst patients with metastatic disease with associated clinical followup, it was noted that the presence of any one of 3 alterations (TP53 mutation, PTEN mutation, or imbalanced chromosome duplication) were associated with dismal outcome [27].

\section{Collecting duct RCC}

Collecting duct RCC represents an extremely rare subtype with a fatal prognosis. Clinically, the disease behaves in a manner similar to metastatic urothelial cancer and the conventional approach to treatment of metastatic disease entails use of platinating agents [28]. Analysis of 17 patients using an aforementioned CLIAA-certified platform (Foundation Medicine, Inc.; Cambridge, MA) identified frequent alterations in NF2 (26\%) and SMARCB1 (20\%), both potentially targetable entities [29]. Wang et al. have published a smaller series of 7 patients with collecting duct carcinoma with available tumor and paired normal tissue [30]. A highlight of this report was the identification of $C D K N 2 A$ alteration in 3 samples [30]. Notably, SLC7A11, a gene associated with cisplatin resistance was identified in 4 out of 5 patients assessed [30].

\section{Sarcomatoid RCC}

Sarcomatoid disease reflects a histologic subtype that can be admixed with any other subtype of RCC $[31,32]$. The presence of sarcomatoid features (and the extent of involvement) correlates with poorer clinical outcomes [33-35]. Malouf and colleagues have characterized a series of 26 patients with sarcomatoid RCC with comparison of genomic data to an 
additional 56 patients with clear cell RCC [36]. Comparison to clear cell, papillary, and chromophobe datasets in the TCGA were also performed [36]. The most common alterations in this cohort were in TP53 (42.3\%), VHL (34.6\%), CDNK2A (26.9\%), and NF2 (19\%) [36]. These data complement a study from our group including 8 patients assessed using RNA sequencing [37]. In this series, upregulation of aurora kinase signaling was noted in sarcomatoid tissue components and increased activity was correlated with increased activation of mTOR pathways [37].

\section{Unclassified RCC}

Unclassified RCC represents a distinct histologic entity with no standard therapy established. A recent trial reported by Voss et al. assessed a regimen of bevacizumab with everolimus in 35 patients with non-clear cell $\mathrm{mRCC}$; interestingly, the vast majority of patients enrolled had unclassified disease $(n=23)$ [38]. Many patients classified as having this diagnosis did demonstrate papillary features, but all diagnoses were independently confirmed. Response rate and progression-free survival (PFS) in this cohort was $29 \%$ and 11 months, respectively. In the cohort of patients with unclassified disease, the presence of papillary features was strongly associated with response.

\section{THE CLINICAL RESEARCH PARADIGM FOR NON-CLEAR CELL RCC}

\section{Histology inclusive trials}

A challenge in interpreting the existing landscape of therapeutic data for non-clear mRCC is that most randomized studies to date include a large mix of histologies. This is demonstrated by the randomized, phase II ESPN trial, comparing sunitinib and everolimus in patients with either papillary, chromophobe, unclassified, translocation (Xp11.2), or clear-cell with $\geq 20 \%$ sarcomatoid features [39]. The study was projected to include 108 treatment-naïve patients with metastatic disease, but was terminated after enrollment of less than 80 patients [39]. No significant difference was appreciated in PFS or overall survival (OS), although the trend in both of these statistics favored sunitinib [39]. A breakdown by histologic subtype reveals a very small number of patients in each subgroup [39]. Papillary disease was best represented, with 28 patients total, but less than 20 patients in the cohort had chromophobe, unclassified, translocation, or sarcomatoid renal cell carcinoma [39].

The ASPEN clinical trial employed a similar trial design, albeit including a more limited array of histologies [40]. The study ultimately enrolled 108 patients with either papillary, chromophobe, or unclassified disease [40]. Like the ESPN trial, patients were randomized to either receive sunitinib or everolimus [40]. The study met its primary endpoint, suggesting that that sunitinib was associated with a significantly improved PFS, increasing PFS from 5.6 to 8.3 months (HR 1.41 [95\% CI 1.03-1.92]; $P=0.16$ ) [40]. Again, however, each subgroup included a small number of patients, with 70 , 16 , and 22 patients with papillary, chromophobe and unclassified disease, respectively [40].

A third randomized study, RECORD-3, was not specific to patients with non-clear cell disease [41]. In a cohort of patients with mRCC of any histology, patients were randomized to receive either sunitinib or everolimus, but with crossover at the time of progression (distinguishing this study design from ASPEN and ESPN) [42]. Amongst 66 patients with non-clear cell histology, a non-significant trend was seen towards improvement in PFS with sunitinib versus everolimus (7.23 months vs 4.09 months; HR 1.54 [95\% CI 0.86-2.75]) [42]. To our knowledge, no data is available regarding the histologic breakdown of this cohort - given this caveat, as with the aforementioned randomized trials, it is challenging to make an informed statement regarding optimal therapy for specific subtypes of non-clear cell RCC.

\section{Histology specific trials}

Histology specific trials for non-clear cell RCC have the benefit of including patients with a uniform biology. However, there are certainly challenges in accruing to studies in these relatively uncommon subsets. Using papillary RCC as an example, several single-arm studies have been performed using MET inhibitors. These studies build on the genomic data outlined previously, which highlight an increased incidence of MET mutation and copy number alteration in both type 1 and 2 disease.

Foretinib, a dual inhibitor antagonizing both VEGFR and MET, was examined in a cohort of 74 patients with metastatic papillary RCC [43]. Response rate in the overall cohort was $13.5 \%$ and PFS was 9.3 months [43]. Notably, median survival in the cohort was not reached [43]. Correlative studies 
included an assessment of germline MET mutation and it appeared that patients bearing this mutation had a much higher rate of response (50\% vs 9\%) [43]. This was the first study to suggest a potential signal of activity in a subpopulation of patients enriched by MET status [43]. A similar signal was seen in the European Organization for the Research and Treatment of Cancer (EORTC) CREATE study [44]. This basket study included a cohort of patients with type 1 papillary RCC treated with the ALK inhibitor crizotinib; notably, the agent is also noted to antagonize signaling through MET [44]. Amongst 4 patients that were noted to have MET alterations, 2 responses were observed $(50 \%)$ [44]. No responses were observed amongst 16 patients with MET negative status or amongst 3 patients with MET indeterminate status [44].

The purest and most potent MET inhibitor examined in the clinic to date, savolitinib, was also assessed in a single arm trial for papillary RCC patients [45]. This study, the largest to date, included 109 patients with any number of prior therapies (excluding MET inhibitors) [45]. The study demonstrated a PFS advantage amongst those patients deemed to have MET driven disease, a composite including $M E T$ copy number, $H G F$ gene amplification, or MET kinase domain mutations [45]. Specifically, PFS was 6.2 months amongst patients with MET driven disease, as compared to 1.4 months with nonMET driven disease (HR 0.33; [95\% CI, 0.20-0.52]; $P<0.001$ ) [45].

Two randomized trials will prospectively assess the rationale for MET targeting in patients with papillary RCC. The first, Southwest Oncology Group (SWOG) 1500 , will randomize patients with papillary mRCC to either sunitinib, crizotinib, cabozantinib, or savolitinib [46]. Sunitinib was selected as a control based on the ESPN, ASPEN, and RECORD-3 trials given that the agent was modestly superior to everolimus in each trial despite the noted shortcomings of these studies [39-41]. It is further notable that sunitinib has been selected as a preferred choice for nonclear cell disease on the basis of these datasets [47]. Rationale for savolitinib and crizotinib is based on the aforementioned single arm studies [45]. Finally, cabozantinib was selected as a comparator given the well-demonstrated role of this drug as a MET inhibitor. In clear cell mRCC, cabozantinib has been shown to be superior to sunitinib and everolimus in both the first and second-line settings, respectively [48]. The study will include a total of 180 patients, and estimates a PFS of 6 months with sunitinib [46].
The study is designed to compare each experimental agent to the comparator arm, with an encouraging response rate in the experimental arm considered to be greater than 10.5 months [46]. In an effort to ensure type 1 papillary patients are enrolled (which would theoretically enrich the study population for MET alterations), an effort will be made to limit recruitment of type 2 patients to roughly one quarter of the study population [46]. Rich correlatives will be conducted to accompany the study, including next generation sequencing of baseline tumor specimens for all patients enrolled [46].

A second trial, SAVOIR, is an industry led effort that will first subject untreated patients with papillary mRCC to genomic profiling at baseline [49]. Patient with MET driven disease will be randomized to receive either sunitinib or savolitinib. Prior systemic therapy with agents other than sunitinib or other MET inhibitors is permitted. The study is identical in size to SWOG 1500 with a plan to randomize 180 patients.

\section{CONCLUSION}

The biologic studies cited herein underscore the diversity of non-clear cell RCC. The four histologies discussed - papillary, chromophobe, collecting duct, and sarcomatoid - by no means represent an all-inclusive list. Genomic datasets are emerging to characterize entities such as Xp11.2 (translocation) RCC and rhabdoid disease. For some of the exquisitely rare subtypes of RCC, it is challenging to foresee large randomized trials to validate optimal therapies. Still, smaller phase II efforts with strong biologic rationale (e.g., application of CDK4/6 inhibitors in collecting duct RCC given frequent $C D K N 2 A$ alteration) is one way to move forward. For more prevalent subtypes such as papillary, we have highlighted some of the trials that focus on disease biology (e.g., SWOG 1500 and SAVOIR) $[46,49]$.

The ability to conduct these focused trials is limited by several factors. The availability and quality of drugs associated with specific molecular alterations is often suboptimal. The association between papillary RCC and MET biology has long been known [50-52]. Several years ago, the SWOG 1107 trial was launched for patients with papillary RCC using a parallel, two-arm design evaluating erlotinib with ARQ197 or ARQ197 alone [53]. The results of the study were dismal, with no responses observed on either 
treatment arm [53]. Subsequent preclinical studies established ARQ197 as a microtubule inhibitor, as opposed to a specific inhibitor of MET $[54,55]$. Thus, an essential step in conceiving trials for non-clear cell RCC is making sure that appropriate drugs are available.

Competing research priorities may also complicate a focus on non-clear cell disease. As is the case currently, trials for clear cell disease may dominate the research agenda for both commercial and non-commercial research groups. To this end, several entities have released position statements that highlight the need for non-clear cell trials. The European Association of Urology Renal Cell Carcinoma Guidelines Panel recently reported a systematic review of non-clear cell research showing a paucity of active studies in this domain [56]. The group applauded efforts such as SWOG 1500 and placed these types of the prospective evaluations of agents for specific histologies at the top of their priority list [56].

Another challenge in clinical research may be the shifting landscape of treatments for clear cell RCC with recent data from CheckMate 214 suggesting an OS advantage with the combination of nivolumab/ipilimumab over sunitinib in the first-line setting [57]. There is biological rationale to envision activity of checkpoint inhibitors in non-clear cell RCC. Choueiri et al. have derived substantial insights from 101 patients with a variety of non-clear cell subtypes [58]. Expression levels of PD-L1 varied in this cohort, with $10 \%$ of papillary patients expressing PDL1 in tumor cells, contrasting with $30 \%$ of Xp11.2 patients expressing PD-L1. When PD-L1 expression was assessed in tumor-infiltrating mononuclear cells, the rates of PD-L1 expression increased to $60 \%$ in papillary RCC and to $90 \%$ in Xp11.2 disease. A similar trend was observed amongst other subtypes. Already, several small datasets have emerged which retrospectively assess the activity of nivolumab in non-clear cell RCC. Koshkin and colleagues have assembled a 41 patient cohort including multiple histologies with a median PFS of 3.5 months and a median OS that has not been reached [59]. Multiple durable responses were noted. It will be critical to rapidly juxtapose the efficacy of checkpoint inhibitors in non-clear cell disease against existing treatments. One proposed idea is to add a checkpoint inhibitor arm onto the current schema for SWOG 1500.

Finally, while classification of non-clear cell RCC is currently still based on microscopic features, it is clear that there are differing molecular subsets within each subtype of RCC. While tissue-based profiling is readily accessible through multiple CLIAcertified labs, there are patients for whom biopsy is not safe or feasible. Furthermore, the genomic profile of archival tissues may not be representative of a patient's current genomic status. Our group characterized circulating tumor DNA (ctDNA) from a series of 224 patients with advanced RCC [60]. Our study confirmed dynamic changes in patients who were receiving first-line therapy versus post-first-line therapy. As a part of this report, we included preliminary data pertaining to patients bearing non-clear cell histology: papillary, chromophobe, and sarcomatoid subtypes. Several actionable mutations were noted in genes including EGFR and NF1. Furthermore, a modest subset of papillary and sarcomatoid patients demonstrated VHL mutation on ctDNA assessment, a hallmark of clear cell disease.

In summary, there are multiple obstacles that belie clinical research for non-clear cell RCC. However, it will not be sufficient simply to group together multiple subtypes of disease into one study - rather, studies must be tailored to individual histologic or molecular subtypes of RCC to maximize gain. While this approach will certainly require a concerted effort from the investigative community, the yield will be substantial for a field in which no true standard of care exists.

\section{ACKNOWLEDGMENTS}

None.

\section{CONFLICT OF INTEREST}

SKP reports consulting agreements with Genentech, Aveo, Eisai, Roche, Pfizer, Novartis, Exelixis, Ipsen, BMS and Astellas, and honoraria from Genentech.

\section{REFERENCES}

[1] Motzer RJ, Bacik J, Murphy BA, et al., Interferon-alfa as a comparative treatment for clinical trials of new therapies against advanced renal cell carcinoma. Journal of Clinical Oncology 2002;20:289-96.

[2] Fyfe G, Fisher RI, Rosenberg SA, et al., Results of treatment of 255 patients with metastatic renal cell carcinoma who received high-dose recombinant interleukin-2 therapy. J Clin Oncol 1995;13:688-96.

[3] Rini BI, Campbell SC, Escudier B: Renal cell carcinoma. Lancet 2009;373:1119-32.

[4] Krieg M, Haas R, Brauch H, et al., Up-regulation of hypoxia-inducible factors HIF-1alpha and HIF-2alpha under normoxic conditions in renal carcinoma cells by 
von Hippel-Lindau tumor suppressor gene loss of function. Oncogene 2000;19:5435-43.

[5] Escudier B, Pluzanska A, Koralewski P, et al., Bevacizumab plus interferon alfa-2a for treatment of metastatic renal cell carcinoma: A randomised, double-blind phase III trial. Lancet 2007;370:2103-11.

[6] Escudier B, Eisen T, Stadler WM, et al., Sorafenib in advanced clear-cell renal-cell carcinoma. N Engl J Med 2007;356:125-34

[7] Motzer RJ, Hutson TE, Tomczak P, et al., Sunitinib versus interferon alfa in metastatic renal-cell carcinoma. $\mathrm{N}$ Engl J Med 2007;356:115-24.

[8] Sternberg CN, Davis ID, Mardiak J, et al., Pazopanib in locally advanced or metastatic renal cell carcinoma: Results of a randomized phase III trial. J Clin Oncol 2010;28: 1061-8.

[9] Motzer RJ, Hutson TE, Cella D, et al., Pazopanib versus sunitinib in metastatic renal-cell carcinoma. N Engl J Med 2013;369:722-31.

[10] Rini BI, Escudier B, Tomczak P, et al., Comparative effectiveness of axitinib versus sorafenib in advanced renal cell carcinoma (AXIS): A randomised phase 3 trial. Lancet 2011;378:1931-9.

[11] Motzer RJ, Hutson TE, Ren $M$, et al., Independent assessment of lenvatinib plus everolimus in patients with metastatic renal cell carcinoma. Lancet Oncol 2016;17:e4-5.

[12] Hudes G, Carducci M, Tomczak P, et al., Temsirolimus, interferon alfa, or both for advanced renal-cell carcinoma. New England Journal of Medicine 2007;356:2271-81.

[13] Motzer RJ, Escudier B, Oudard S, et al., Efficacy of everolimus in advanced renal cell carcinoma: A doubleblind, randomised, placebo-controlled phase III trial. Lancet 2008;372:449-56.

[14] Choueiri TK, Escudier B, Powles T, et al., Cabozantinib versus Everolimus in Advanced Renal-Cell Carcinoma. N Engl J Med 2015;373:1814-23.

[15] Rini BI, Atkins MB: Resistance to targeted therapy in renalcell carcinoma. Lancet Oncol 2009;10:992-1000.

[16] Weinstock M, McDermott D: Targeting PD-1/PD-L1 in the treatment of metastatic renal cell carcinoma. Ther Adv Urol 2015;7:365-77.

[17] Massari F, Ciccarese C, Santoni M, et al., Targeting fibroblast growth factor receptor (FGFR) pathway in renal cell carcinoma. Expert Rev Anticancer Ther 2015;15:1367-9.

[18] Yu H, Liu R, Ma B, et al., Axl receptor tyrosine kinase is a potential therapeutic target in renal cell carcinoma. British Journal of Cancer 2015;113:616-25.

[19] Giubellino A, Linehan WM, Bottaro DP: Targeting the Met signaling pathway in renal cancer. Expert Rev Anticancer Ther 2009;9:785-93.

[20] Matsuki M, Adachi Y, Ozawa Y, et al., Targeting of tumor growth and angiogenesis underlies the enhanced antitumor activity of lenvatinib in combination with everolimus. Cancer Sci 2017;108:763-71.

[21] Yakes FM, Chen J, Tan J, et al., Cabozantinib (XL184), a novel MET and VEGFR2 inhibitor, simultaneously suppresses metastasis, angiogenesis, and tumor growth. Mol Cancer Ther 2011;10:2298-308.

[22] Hudes G, Carducci M, Tomczak P, et al., Temsirolimus, interferon alfa, or both for advanced renal-cell carcinoma. N Engl J Med 2007;356:2271-81.

[23] Cancer Genome Atlas Research N, Linehan WM, Spellman PT, et al., Comprehensive Molecular Characterization of Papillary Renal-Cell Carcinoma. N Engl J Med 2016;374:135-45.
[24] Pal SK, Ali SM, Yakirevich E, et al., Characterization of Clinical Cases of Advanced Papillary Renal Cell Carcinoma via Comprehensive Genomic Profiling. Eur Urol 2017. [E-pub ahead of print].

[25] Storkel S, Eble JN, Adlakha K, et al., Classification of renal cell carcinoma: Workgroup No. 1. Union Internationale Contre le Cancer (UICC) and the American Joint Committee on Cancer (AJCC). Cancer 1997;80:987-9.

[26] Davis CF, Ricketts CJ, Wang M, et al., The somatic genomic landscape of chromophobe renal cell carcinoma. Cancer Cell 2014;26:319-30.

[27] Casuscelli J, Weinhold N, Gundem G, et al., Genomic landscape and evolution of metastatic chromophobe renal cell carcinoma. JCI Insight 2017;2.

[28] Kwon KA, Oh SY, Kim HY, et al., Clinical features and treatment of collecting duct carcinoma of the kidney from the korean cancer study group genitourinary and gynecology cancer committee. Cancer Res Treat 2014;46:141-7.

[29] Pal SK, Choueiri TK, Wang K, et al., Characterization of Clinical Cases of Collecting Duct Carcinoma of the Kidney Assessed by Comprehensive Genomic Profiling. Eur Urol 2016;70:516-21.

[30] Wang J, Papanicolau-Sengos A, Chintala S, et al., Collecting duct carcinoma of the kidney is associated with CDKN2A deletion and SLC family gene up-regulation. Oncotarget 2016;7:29901-15.

[31] Shuch B, Bratslavsky G, Linehan WM, et al., Sarcomatoid renal cell carcinoma: A comprehensive review of the biology and current treatment strategies. Oncologist 2012;17:46-54.

[32] Shuch B, Amin A, Armstrong AJ, et al., Understanding pathologic variants of renal cell carcinoma: Distilling therapeutic opportunities from biologic complexity. Eur Urol 2015;67:85-97.

[33] Cheville JC, Lohse CM, Zincke H, et al., Sarcomatoid renal cell carcinoma: An examination of underlying histologic subtype and an analysis of associations with patient outcome. Am J Surg Pathol 2004;28:435-41.

[34] Shuch B, La Rochelle JC, Wu J, et al., Performance status and cytoreductive nephrectomy: Redefining management in patients with poor performance. Cancer 2008;113: 1324-31.

[35] Moch H, Gasser T, Amin MB, et al., Prognostic utility of the recently recommended histologic classification and revised TNM staging system of renal cell carcinoma: A Swiss experience with 588 tumors. Cancer 2000;89:604-14.

[36] Malouf GG, Ali SM, Wang K, et al., Genomic Characterization of Renal Cell Carcinoma with Sarcomatoid Dedifferentiation Pinpoints Recurrent Genomic Alterations. Eur Urol 2016;70:348-57.

[37] Pal SK, He M, Tong T, et al., RNA-seq reveals aurora kinase-driven mTOR pathway activation in patients with sarcomatoid metastatic renal cell carcinoma. Mol Cancer Res 2015;13:130-7.

[38] Voss MH, Molina AM, Chen YB, et al., Phase II Trial and Correlative Genomic Analysis of Everolimus Plus Bevacizumab in Advanced Non-Clear Cell Renal Cell Carcinoma. J Clin Oncol 2016;34:3846-53.

[39] Tannir NM, Jonasch E, Albiges L, et al., Everolimus Versus Sunitinib Prospective Evaluation in Metastatic Non-Clear Cell Renal Cell Carcinoma (ESPN): A Randomized Multicenter Phase 2 Trial. Eur Urol 2016;69:866-74.

[40] Armstrong AJ, Halabi S, Eisen T, et al., Everolimus versus sunitinib for patients with metastatic non-clear cell renal cell carcinoma (ASPEN): A multicentre, open-label, randomised phase 2 trial. Lancet Oncol 2016;17:378-88. 
[41] Knox JJ, Barrios CH, Kim TM, et al., Final overall survival analysis for the phase II RECORD-3 study of first-line everolimus followed by sunitinib versus first-line sunitinib followed by everolimus in metastatic RCC. Annals of Oncology 2017;28:1339-1345.

[42] Motzer RJ, Barrios CH, Kim TM, et al., Phase II randomized trial comparing sequential first-line everolimus and secondline sunitinib versus first-line sunitinib and second-line everolimus in patients with metastatic renal cell carcinoma. J Clin Oncol 2014;32:2765-72.

[43] Choueiri TK, Vaishampayan U, Rosenberg JE, et al., Phase II and biomarker study of the dual MET/VEGFR2 inhibitor foretinib in patients with papillary renal cell carcinoma. J Clin Oncol 2013;31:181-6.

[44] Schoffski P, Wozniak A, Escudier B, et al., Crizotinib achieves objective responses and long-lasting disease control in patients (pts) with metastatic papillary renal cell carcinoma type 1 (PRCC1) with somatic MET mutations. EORTC phase II trial 90101 "CREATE”. Cancer Research 2016;76.

[45] Choueiri TK, Plimack E, Arkenau HT, et al., BiomarkerBased Phase II Trial of Savolitinib in Patients With Advanced Papillary Renal Cell Cancer. J Clin Oncol 2017;35:2993-3001.

[46] Pal SK, Tangen CM, Thompson IM, et al., A randomized, phase II efficacy assessment of multiple MET kinase inhibitors in metastatic papillary renal carcinoma (PRCC): SWOG S1500. Journal of Clinical Oncology 2017;35:TPS4599-TPS4599.

[47] Motzer RJ, Jonasch E, Agarwal N, et al., Kidney Cancer, Version 2.2017, NCCN Clinical Practice Guidelines in Oncology. J Natl Compr Canc Netw 2017;15:804-34.

[48] Ruiz-Morales JM, Heng DY: Cabozantinib in the treatment of advanced renal cell carcinoma: Clinical trial evidence and experience. Ther Adv Urol 2016;8:338-47.

[49] Choueiri TK JR, Ghiorghiu D, Haddad V, Kohlmann A, Frigault MM, Ottesen L: 924TiPSavolitinib versus sunitinib in patients with MET-driven, unresectable and locally advanced or metastatic papillary renal cell carcinoma: SAVOIR, a randomised, phase III trial. Annals of Oncology 2017;28.

[50] Schmidt L, Duh FM, Chen F, et al., Germline and somatic mutations in the tyrosine kinase domain of the MET protooncogene in papillary renal carcinomas. Nature Genetics 1997;16:68-73.
[51] Schmidt L, Junker K, Nakaigawa N, et al., Novel mutations of the MET proto-oncogene in papillary renal carcinomas. Oncogene 1999;18:2343-50.

[52] Fischer J, Palmedo G, von Knobloch R, et al., Duplication and overexpression of the mutant allele of the MET protooncogene in multiple hereditary papillary renal cell tumours. Oncogene 1998;17:733-9.

[53] Twardowski P, Plets M, Plimack ER, et al., SWOG 1107: Parallel (randomized) phase II evaluation of tivantinib (ARQ-197) and tivantinib in combination with erlotinib in patients (Pts) with papillary renal cell carcinoma (pRCC). Journal of Clinical Oncology 2015;33.

[54] Katayama R, Aoyama A, Yamori T, et al., Cytotoxic Activity of Tivantinib (ARQ 197) Is Not Due Solely to c-MET Inhibition. Cancer Research 2013;73:3087-96.

[55] Basilico C, Pennacchietti S, Vigna E, et al., Tivantinib (ARQ197) Displays Cytotoxic Activity That Is Independent of Its Ability to Bind MET. Clinical Cancer Research 2013;19:2381-92.

[56] Fernandez-Pello S, Hofmann F, Tahbaz R, et al., A Systematic Review and Meta-analysis Comparing the Effectiveness and Adverse Effects of Different Systemic Treatments for Non-clear Cell Renal Cell Carcinoma. Eur Urol 2017;71:426-36.

[57] Escudier B ea: CheckMate 214: Efficacy and safety of nivolumab+ipilimumab $(\mathrm{N}+\mathrm{I})$ vsunitinib $(\mathrm{S})$ for treatmentnaïve advanced or metastatic renal cell carcinoma (mRCC), including IMDC risk and PD-L1 expression subgroups. 2017.

[58] Choueiri TK, Fay AP, Gray KP, et al., PD-L1 expression in nonclear-cell renal cell carcinoma. Ann Oncol 2014;25:2178-84.

[59] Koshkin VS, Barata PC, Vogelzang NJ, et al., Nivolumab treatment for patients with non-clear cell renal cell carcinoma: A multicenter retrospective analysis. Journal of Clinical Oncology 2017;35:4586.

[60] Maia MC BP, Dizman N, Hsu J, Jones J, Lanman RB, Banks KC, Pal SK: Association of Circulating Tumor DNA (ctDNA) Detection in Metastatic Renal Cell Carcinoma (mRCC) with Tumor Burden. Kidney Cancer 2017;1:65-70. 